\title{
Neonatal Outcomes and Mental Illness, Substance Abuse, and Intentional Injury During Pregnancy
}

Anna Wiencrot, MPH, University of Illinois-Chicago

annawiencrot@gmail.com

Angela Nannini, PhD, FNP-C, University of Massachusetts Lowell

Angela_Nannini@uml.edu

Susan E. Manning, MD, MPH, Massachusetts Department of Public Health

Susan.E.Manning@state.ma.us

Joan Kennelly, PhD, MPH, University of Illinois-Chicago

kennelly@uic.edu 


\begin{abstract}
Objectives: Mental illness (MI), substance abuse (SA), and intentional injury (II) are known individual risk factors for adverse pregnancy outcomes. Their combined association with preterm birth (PTB) and low birth weight (LBW) remains relatively unexplored. We examined hospital utilization for the co-occurrence of II and MI or SA in pregnant women in Massachusetts and assessed their interactive association with PTB and LBW.
\end{abstract}

Methods: This retrospective cohort study used ICD-9 and E-codes reported on linked birth and hospital utilization data to identify MI, SA, and II diagnoses during pregnancy for 176,845 Massachusetts resident women who delivered during 2002-2004. Adjusted odds ratios (OR) for the independent and joint associations of MI, SA, and II on PTB and LBW were calculated.

Results: 2,208 women (1.6\%) had a prenatal MI visit, $834(0.5 \%)$ a prenatal SA visit, and $847(0.5 \%)$ a prenatal II visit. Among them 163 women had MI and II visits and 69 had SA and II visits. SA, MI, and II were all significant predictors of LBW and PTB. Women with both SA and II had higher odds of PTB (OR 2.7 95\% CI 1.3-5.7) and LBW (OR 5.3 95\% CI 3.9-7.3) than women with neitherdiagnosis.

Conclusions: Prenatal MI, SA, and II are risk factors for LBW and PTB. Women with SA and II co-diagnoses have greater risk of LBW and PTB than women with neither diagnosis. Screening, timely diagnosis, and treatment of women with co-occurring morbidities, particularly II and SA, should be incorporated into reproductive and perinatal health programs.

Keywords: intentional injury, mental illness, substance abuse, pregnancy, co-morbidities 


\section{Introduction}

Mental illness (MI), substance abuse (SA), and intentional injury (II) are well-established risk factors for adverse neonatal outcomes. Estimating the burden of these conditions during pregnancy is difficult due to the masking of MI symptoms by physical complaints of pregnancy; social stigma; inadequate training of clinical providers on assessment and treatment during pregnancy; and limited screening tools for use specifically during pregnancy. Additionally, definitions and diagnostic criteria used in published studies vary greatly. The prevalence of MI, SA, and II co-morbidity and their consequences on neonatal outcomes including preterm birth (PTB) and low birthweight (LBW) have been studied to a lesser degree. This study examines prenatal hospital utilization for II among women with MI or SA during pregnancy and identifies characteristics of women with these co-morbidities. The interactive associations of MI or SA and II on PTB and LBW are also explored.

\section{Individual Risk Factors}

MI, and depression in particular, has been studied more often than II and SA. Some women experience their first episode of depression during pregnancy, and pregnant women with a history of depression are at higher risk of recurrence or increased severity of their symptoms (1). An estimated $20 \%$ of women experience depressive symptoms (first time and recurrent) at some point during pregnancy (2). The prevalence of major or minor depression diagnoses is estimated at $11.0 \%$ in the first trimester and $8.5 \%$ in the second and third trimesters (3). Depression during pregnancy is associated with increased risk of PTB, decreased fetal growth, and LBW (4-9), although definitions and 
measurement vary. Studies of perinatal depression include treated and/or untreated depression, depressive symptoms, and depression diagnoses with a range of severity. In addition to depression, anxiety disorders, including panic disorders, obsessivecompulsive disorders, and post-traumatic stress disorder (PTSD), are also associated with poor neonatal outcomes $(4,6,10)$.

Rates of serious MI during pregnancy, while low, are of concern given their association with adverse outcomes and the effects of psychotropic medication use or discontinuation during pregnancy. In a population-based study of pregnant women in Sweden, the prevalence of preexisting schizophrenia was $0.13 \%$, and a significant association with stillbirth, infant death, PTB and LBW was observed (12).

Prenatal estimates of SA also vary by assessment methods (e.g., maternal report, urine test). The 1992 National Pregnancy and Health Surveyfound the prevalence of any illegal drug use during pregnancy to be 5.5\% (13). In the 2004-05 National Survey on Drug Use and Health, 3.9\% of pregnant women aged 15-44 years reported using illicit drugs in the past month, a rate significantly lower than that reported by non-pregnant women in the same age group (9.9\%). While an estimated $12.1 \%$ of pregnant women reported alcohol use and 3.9\% reported binge drinking, the rate of heavy drinking reported during pregnancy was $0.7 \%$ (14). Prenatal alcohol abuse has been linked to fetal alcohol syndrome, poor cognitive and behavioral outcomes, developmental delays, PTB and LBW (15). Illicit drug use during pregnancy is associated with PTB, LBW, small head circumference, miscarriage, genitourinary infection, congenital malformations, IUGR, nervous system damage, higher rates of NICU admission and prolonged maternal and infant hospital stays $(13,16,17)$. 
Most studies of intentional injury during pregnancy focus on intimate partner violence (IPV) and report prevalence estimates between $3.9 \%$ and $8.3 \%$; II estimates overall however, range from $0.9 \%$ to $20.1 \%$ (18). Although population-based studies of IPV during pregnancy are rare, a recent study found that $13.6 \%$ of women had at least one hospital visit for a pregnancy-associated injury; $1 \%$ of these visits were for II (19). There is substantial research on the consequences of violence during pregnancy. A systematic review of the effects of physical violence on pregnancy outcomes found an increased likelihood for kidney infections, operative delivery, inadequate weight gain, LBW, PTB, SGA, fetal death, and maternal mortality (20).

\section{Co-morbid Risk Factors}

MI, SA, and II often co-occur during pregnancy; however, there is little research on the intersection and relationships among these co-morbidities, particularly between MI and II.

A study on co-morbidities examined MI/II and SA/II in a prospective cohort of primarily minority low-income women (21). The researchers found that women experiencing violence during pregnancy were more likely to have a history of depression, suicide attempts, heavy alcohol use, and heavy illicit drug use, and a weak association between violence and poor neonatal outcomes was reported. A later study also found that women experiencing physical violence during pregnancy were more likely to use alcohol and illicit drugs (22).

A number of studies conducted in the late 1990s and early 2000s examined SA and II. Martin et al. (23) surveyed 2,000 prenatal patients and found that victims of violence were more likely than non-victims to engage in SA throughout pregnancy. 
Conversely, a 1998 study of 84 low-income women enrolled in a prenatal SA program found no significant difference in prevalence of SA between women with and without a history of exposure to violence (24). A study of 703 pregnant adolescents found that those who used illicit drugs during pregnancy were more likely to experience physical abuse than non-users. Alcohol users were also more likely to be victims of physical violence than non-users (25).

Horrigan et al. (26) studied 271 prenatal patients in Ohio. Women with SA were more likely to have a history of depression and exposure to violence. Velez et al. (27) found that, among 715 pregnant substance-abusing women, $20 \%$ had experienced physical abuse at some point during their lives. However, a study of 207 Swedish pregnant women found no association between SA and violence during pregnancy (28).

Looking at all three risk factors, Tuten et al. (29) observed that substancedependent pregnant women currently experiencing violence were significantly more likely to have lifetime drug use, current major depression, and other MI (e.g., schizophrenia, paranoia) compared to substance-dependent pregnant women not currently experiencing violence. Bacchus (30) examined the prevalence of domestic violence and its associations with obstetric complications, psychological health, and drug use among 100 pregnant and postpartum women. While no association between a history of domestic violence and drug use was found, higher depression scores were associated with a history of violence. Domestic violence history and high depression scores were also associated with obstetric complications.

Studies of low-income women in Brazil found a significant relationship between MI and II during pregnancy. In one study $(n=204)$ there was a strong association between 
violence during pregnancy and depression (31). Another study (n=930) found that women experiencing lifetime violence and/or violence during pregnancy were more likely to have MI, compared to women without any exposure to violence. Violence during pregnancy and MI had significant independent effects on LBW (32).

Rosen et al. (33), using data from the first three waves of the Women's Employment Study, examined the effects of prenatal mental health and exposure to violence on LBW for 148 welfare recipients in Michigan. After controlling for other factors, exposure to violence and MI (PTSD and/or depression) were significant predictors of LBW. The combination of MI and violence was also significantly associated with LBW.

Most recently, Rodriguez et al. (34) interviewed 210 pregnant Latina women in Los Angeles to examine factors related to prenatal depression, PTSD, and IPV. IPV was significantly associated with depression, but not PTSD.

Overall, the literature on the relationship of these co-morbid factors is based on cross-sectional studies using surveys and questionnaires with relatively small sample sizes and different assessment methods (Table 1). Prevalence estimates of individual and combined risk factors as well as the strength of their association with neonatal outcomes vary considerably.

The purpose of this study was to contribute to the literature on the co-morbidity of MI, SA and II as risk factors for adverse perinatal outcomes. We examined the following questions: Among women giving birth in Massachusetts, what is the prevalence of hospital utilization for II during pregnancy for women with MI or SA? What are the characteristics of women hospitalized during pregnancy with these co-morbidities? Is 
there an interactive effect of II and MI or SA on PTB and LBW?

\section{Research Design and Methods \\ Data Set}

Data were derived from the Massachusetts Pregnancy to Early Life Longitudinal (PELL) data system. PELL is a unique, population-based data system, with multiple linked data sets allowing cross-sectional and longitudinal analyses. Using deterministic and probabilistic methods, PELL links birth certificates and fetal death reports to the delivery-related hospital discharge records of mothers and live born infants. This core data set is then linked to maternal hospital utilization records for inpatient, emergency department (ED) or observation stay (OS, less than 24 hour) visits that occurred prenatally and postpartum. For this study, the 16 available diagnosis fields on each hospital utilization record for hospital visits (inpatient, ER, and OS) occurring during pregnancy were examined. Detailed information on the PELL linkage methodology has been published elsewhere (35).

Hospital utilization data were provided by the Massachusetts Division of Health Care Finance and Policy and birth certificate data were provided by the Massachusetts Department of Public Health Registry of Vital Records and Statistics.

\section{Study Design and Inclusion Criteria}

This retrospective cohort study included Massachusetts resident women with instate live births greater than 20 weeks gestation or weighing over 350 grams, whose pregnancies began after September 30, 2001 and whose first postpartum year ended before December 30, 2004. The final study population included 176,845 women. 


\section{Study Variables}

MI and SA diagnoses were identified with ICD-9 and E-codes using the Agency for Health Care Research and Quality Mental Health Substance Abuse Clinical Classification Software (CSS-MHSA). SA diagnoses included the use of both legal drugs, including alcohol, and illegal drugs.

II diagnoses were identified with ICD-9 and E-codes. II includes both selfinflicted and other-inflicted injuries. The ICD-9 diagnostic codes 800-999.99 indicate the type of injury and sometimes location on the body (36). The E-code supplementary classification of external causes of injury and poisoning indicate intent and the cause of the injury, if known. Late effects of injuries, adverse drug effects, and medical carerelated injuries were excluded. E-codes were available for $95.8 \%$ of injury hospitalizations records (19).

PTB was defined as less than 37 weeks and LBW was defined below 2500 grams. Independent variables that were known to be associated with the birth outcomes of interest were examined, including maternal age, race/ethnicity, delivery payer, maternal education, marital status, parity, smoking (any smoking during pregnancy). Delivery payer source was obtained from the hospital discharge data at delivery; birth certificate data was used if discharge insurance information was not available. Birth certificate data was used for all other socioeconomic descriptors of the study population.

\section{Analytic Strategy}

Univariate and bivariate analyses were run for all maternal variables to examine distributions and assess for confounding. Logistic regression calculated unadjusted and 
adjusted odds ratios (ORs) for the independent and joint associations of MI, SA, and II with PTB and LBW. Separate models were used to estimate these associations. The model for the MI, SA and II analyses controlled for maternal age, race/ethnicity, payer, marital status, and smoking during pregnancy; additionally, the model for MI/II analysis controlled for SA and the model for SA/II analysis controlled for MI.

Statistical analyses employed SAS Version 9.3 software (SAS Institute, Cary, NC, USA). The study was approved by the Massachusetts Department of Public Health Research and Data Access Review Committee/Institutional Review Board (IRB), the Northeastern University IRB, and the University of Massachusetts Lowell IRB.

\section{Results}

During the study period, 176,845 Massachusetts women had one or more live births; approximately $7 \%$ of those births were LBW and $10 \%$ were preterm. A total number of 120,379 hospital visits during pregnancy occurred during the study period. Selected demographics for the entire study population, as well as by type of hospital visit, are presented in Table 2 . The majority of the study population was older than 30 years (56\% of births were 30 years or older), educated ( $65 \%$ of women had more than a high school education), married (72.5\%), non-smokers (85.4\%), and primarily non-Hispanic white $(71.5 \%)$. Women with at least one visit for MI, SA, or II were significantly younger, less likely to have more than a high school education or to be married, and more likely to have public insurance and to smoke than women without visits. Women with at least one SA or II visit were also less likely to be non-Hispanic white. Demographics for women with self-inflicted versus other-inflicted injury were not significantly different. 
A total of 2,208 women (1.3\%) had a hospital visit during pregnancy for MI, 834 $(0.5 \%)$ for SA, and $847(0.5 \%)$ for II. Slightly less than $3 \%$ of the total hospital visits during pregnancy were for MI; $1.2 \%$ for SA and $0.8 \%$ for II (Table 3).

Tables 4 and 5 present unadjusted odds ratios and highlight the co-occurrence of MI, SA, and II visits. Among the 847 women with II visits, 163 (19\%) also had a prenatal MI visit. Demographics and unadjusted ORs for women with both II and MI visits are presented in Table 4. These women were more likely to be Hispanic or nonHispanic black, younger, unmarried, have less than a high school education, use public insurance, and smoke than women without II/MI visits (Table 4). Eight percent $(n=69)$ of women with a hospital visit during pregnancy for II also had a visit for SA; these demographics and unadjusted ORs are shown in Table 5. In all racial/ethnic groups, women who had hospital visits for SA and II were more likely to be young, unmarried, have a high school or less education, use public insurance, and smoke than women without SA/II visits. Finally, 6\% (n=49) of the women with II had both an MI and SA visit during the prenatal period (data not shown).

Table 6 presents the association of each risk factor (MI, SA, and II) with LBW and PTB. Women with co-morbidities of SA and II compared to women with neither had both higher odds of PTB (OR 2.7 95\% CI 1.3-5.7) and LBW birth (OR 5.3 95\% CI 3.97.3). An association was not observed between the co-morbidity of MI and II and PTB (OR 1.2, 95\% CI 0.7-2.0) or LBW (OR 1.3, 95\% CI 0.8-2.2).

\section{Discussion}

While consistent with other studies in confirming prenatal MI, SA, and II as risk factors for LBW and PTB, our findings highlight the significance of the co-occurrence of these 
factors. A small but important number of women experienced more than one of these risk factors during pregnancy. Women with co-occurring risk factors were more likely to be less educated, unmarried, and publicly insured than their counterparts without comorbid diagnoses. Women hospitalized with diagnoses of both MI and II during pregnancy were more likely to be Hispanic or non-Hispanic black, while women hospitalized with both SA and II had an increased risk of LBW and PTB.

Existing studies on the intersection of MI, SA, and II tend to be cross-sectional surveys or interviews, with small samples. To our knowledge, there are no published studies that examine these co-morbidities using longitudinal hospital or population-based data. This study examines the reproductive outcomes of women with co-morbid MI, SA, and II as coded on hospital visits in the PELL data system, and contributes to the existing research on hospital utilization for and outcomes related to these co-occurring risk factors. While the rates of diagnoses and hospitalizations reported here are generally lower than those found in other studies, the findings reinforce the need for increased awareness and treatment of co-morbidities during pregnancy.

This study illustrates how longitudinally linked data are useful for examining risk factors and combinations of risk factors and their associations with adverse birth outcomes. The redundancy provided by longitudinal data improves the identification of medical conditions. Use of administrative data in a study of substance abuse, mental illness and injury avoids the risk of recall bias and social desirability bias. Combining statewide hospital utilization data over multiple years allowed for sufficient sample size to conduct multivariate analyses and assess the independent as well as joint effects of the variables of interest. 
Despite its strengths, the study has a few limitations. First, this study severely underestimates the prevalence of MI, SA, and II during pregnancy. The PELL dataset only includes acute hospital visits; no data are included for ambulatory care or regular prenatal care visits. These acute hospital visits may represent only the most severe cases of these diagnoses or those women for whom hospital care, rather than ongoing care in another setting, may be the only option. Cultural or socioeconomic issues may also influence whether or not a woman decides to seek treatment as well as how her symptoms of MI or violence are presented, perceived, or diagnosed by the physician. Additionally, the hospital data give no indication of whether the woman was receiving treatment for her MI or SA issues.

Second, coding practices may differ among providers and hospitals, thereby potentially affecting the counts of all three diagnoses. Hospital discharge data vary in quality and consistency (37). E-coding, in particular, is problematic (38). Methods for screening and documenting II also vary greatly among hospitals (36). It is unclear if these differences would have a differential impact on the results of this study.

Third, although frequently used in the literature as a marker of infant and maternal health, assessment of gestational age to determine PTB poses methodological challenges. The PELL dataset contains a variable for calculated gestational age that is based on the date of last menstrual period as indicated on the birth certificate. If this value is not available, the gestational age is generated from the clinical estimate on the birth certificate. There is potential for error in both of these methods of estimation (39). However, it is not likely that error in assessment for gestational age would have biased the results of this study, as there is not known to be differential classification based on 
MI, SA or II status.

Fourth, while combining self-inflicted and other-inflicted injury groups increased our sample size and the power of the study, the groups may have differed in ways that were not measured. However, the two groups were compared on maternal characteristics and the outcomes of interest and they were not significantly different.

Fifth, there are many factors that contribute to PTB and LBW that were not examined in this study; it is possible that other maternal or fetal conditions may have influenced the adverse neonatal outcomes.

Finally, this study may not be generalizable outside of Massachusetts as its unique health care system may have influenced emergency department usage. Massachusetts also has a greater majority of white residents and a lower poverty rate than the U.S. overall $(40,41)$.

Despite study limitations, clearly MI, SA and II diagnoses and hospital visits for both independently and co-occurring are associated with poor neonatal outcomes. Identifying and addressing these risk factors during pregnancy should be a priority across disciplines. This study found that women with co-morbid diagnoses were disproportionately disadvantaged; they were far more likely to be on public insurance than private, and to have lower educational attainment than that of women giving birth without co-morbid diagnoses. Previous studies have determined that low SES is a risk factor for MI, SA, and II $(33,42)$. The fact that these women may face barriers to screening and treatment and likely have other risk factors beyond those studied here, underscores the importance of addressing these conditions.

While this study supports the existing literature on MI, SA, and II diagnoses as 
risk factors for LBW and PTB, it also demonstratesthe increased likelihood of adverse neonatal outcomes is higher in women with both prenatal SA and II. Given the significant findings in the association of the three individual risks factors with LBW and PTB, but the not significant finding of the association of MI/II and LBW and PTB, it is likely that substance abuse is driving the odds ratios. Although a small sample, women affected by the co-morbidities of MI or SA and II in this study are disadvantaged compared with women without these co-morbidities. Programs seeking to improve neonatal outcomes often approach MI, SA and II as independent and single risk factors. Current methods of service delivery are often siloed and fragmented with limited "cross-training" among multi-disciplinary providers (43). Strategies are needed to identify and assist women with co-morbidities of MI, SA and II. Most treatment settings for MI or SA do not routinely assess women for trauma (44). However, even if treatment facilities provide both mental health and SA services, only 32-37\% of these providers, excluding facilities operated by tribal governments, also offer domestic violence services (45).

Raisingawareness of the co-occurrence of these risk factors iscritical to promoting the overall and reproductive health of women. Likewise, an increased focus on multidisciplinary provider training, along with comprehensive and integrated screening for MI, SA and II in primary care is warranted for all women of childbearing age, but especially pregnant women. The current system of case management services for highrisk pregnant women and families might serve as a good point of entry in implementing such an approach. 


\section{Acknowledgements:}

The authors thank the Maternal and Child Health Epidemiology Program, Applied Sciences Branch, Division of Reproductive Health, National Center for Chronic Disease Prevention and Public Health Promotion, Centers for Disease Control and Prevention and the Human Resources and Services Administration, Maternal and Child Health Bureau, for scientific guidance on this analysis and manuscript. 
Table 1: Assessment tools used in reviewed studies, by risk factor ${ }^{\mathrm{a}}$

Assessment tool

Violence Assessment

Abuse Assessment Screen (AAS) $(25,30,34)$

Californian Perinatal Assessment (32)

Conflicts Tactics Scale (CTS) (modified) (33)

Conflicts Tactics Scales 2 (22)

Severity of Violence Against Women Scale (SVAW) (28)

Social Service Review Questionnaire (SSR) (26)

Violence Exposure Questionnaire (VEQ)

Women's Psychosocial History (29)

Substance Use Assessment

Addiction Severity Index (ADI) (29)

Addiction severity before and during pregnancy ${ }^{\mathrm{f}}$

Michigan Alcohol Screening Test and Drug

Abuse Screening Tests (22)

Substance Abuse Subtle Screening Inventory

(SASSI) (26)

University of Michigan Composite

International Diagnostic Interview (UM-CIDI)

\section{Mental Illness Assessment}

Beck Depression Inventory Fast Screen (BDI-

FS) (34)

Center for Epidemiological Studies-

Depression Scale (CES-D) (21)

Composite International Diagnostic Interview

(CIDI) $(31,32)$

Alcohol and drug abuse before and during pregnancy

Substance abuse during pregnancy ${ }^{\mathrm{f}}$

Substance abuse during pregnancy ${ }^{\mathrm{d}}$

Risk factor assessed

Exposure to violence (time period assessed varied by study) $)^{b}$

Current and lifetime exposure to violence ${ }^{c}$

Exposure to violence during pregnancy ${ }^{\mathrm{d}}$

Exposure to violence during pregnancy ${ }^{\mathrm{e}}$

Exposure to violence during pregnancy ${ }^{\mathrm{f}}$

History of exposure to violence ${ }^{\mathrm{f}}$

Lifetime exposure to violence ${ }^{\mathrm{g}}$

Exposure to violence during pregnancy ${ }^{\mathrm{f}}$

Edinburgh Postnatal Depression Scale (EPDS)

Postpartum depression ${ }^{\mathrm{i}}$

Minnesota Multiphasic Personality Inventory-

2 (MMPI-2) (29)

Mental health symptoms during pregnancy ${ }^{\mathrm{f}}$

PTSD Checklist, civilian version (PCL-C) (34)

PTSD during pregnancy ${ }^{\mathrm{f}}$

Structured Clinical Interview for DSM-III-R (SCID) (29)

Axis I disorders during pregnancy ${ }^{\mathrm{f}}$

Symptom Check List-90 (SCL-90) (24)

Mental health symptoms during pregnancy ${ }^{\mathrm{f}}$

University of Michigan Composite International Diagnostic Interview (UM-CIDI) (33) 
${ }^{a}$ Not all reviewed studies are included in this table, as some used interview only (no established assessment tool) or did not describe the assessment method.

${ }^{\mathrm{b}}$ Timing varied by study: Bacchus et al.: Prenatal and postpartum; Martin et al.: Prenatal; Rodriguez et al.: Prenatal

${ }^{\mathrm{c}}$ Postpartum (4-48 hours after delivery)

${ }^{\mathrm{d}}$ Postpartum (most recent birth within 5 years)

${ }^{\mathrm{e}}$ Prenatal (6th or 7 th month)

${ }^{\mathrm{f}}$ Prenatal

${ }^{g}$ Prenatal (most women interviewed during second trimester)

${ }^{\text {h}}$ Prenatal and postpartum

${ }^{\mathrm{i}}$ Timing varied by study: Lovisi et al.: Prenatal (third trimester); Ferri et al.: Postpartum (4-48 hours after delivery) 
Table 2: Distribution of study variables overall and by hospital visit type

\begin{tabular}{|c|c|c|c|c|c|c|}
\hline & \multirow[b]{3}{*}{$\begin{array}{c}\text { Overall study } \\
\text { population } \\
(\mathrm{N}=176,845)\end{array}$} & \multicolumn{4}{|c|}{ By visit type } \\
\hline & & & \multicolumn{4}{|c|}{ At least one prenatal hospital visit for: ${ }^{\text {ab }}$} \\
\hline & & & $\begin{array}{c}\text { Mental } \\
\text { illness } \\
(\mathrm{MI}) \\
(\mathrm{n}=2,208)\end{array}$ & $\begin{array}{c}\text { Substance } \\
\text { abuse } \\
(\mathrm{SA}) \\
(\mathrm{n}=834)\end{array}$ & $\begin{array}{c}\text { Intentional } \\
\text { injury (II) } \\
(\mathrm{n}=847)\end{array}$ & $\begin{array}{c}\text { No MI, SA, } \\
\text { or II } \\
(\mathrm{n}=173,480)\end{array}$ \\
\hline \multicolumn{2}{|c|}{ Characteristic } & \multicolumn{5}{|c|}{$\%$} \\
\hline \multirow{5}{*}{$\begin{array}{l}\text { Maternal } \\
\text { race/ethnicity }\end{array}$} & Hispanic & 12.3 & 17.9 & 16 & 28.3 & 12.1 \\
\hline & White, non-Hispanic & 71.5 & 66.3 & 69.3 & 43.8 & 71.8 \\
\hline & Black, non-Hispanic & 7.4 & 10.9 & 12.2 & 22.6 & 7.3 \\
\hline & Asian/Pacific Islander & 6.7 & 2.1 & 0.7 & 1.7 & 6.8 \\
\hline & Other & 2.0 & 2.9 & 1.8 & 3.7 & 2 \\
\hline \multirow{5}{*}{$\begin{array}{l}\text { Maternal age, } \\
\text { years }\end{array}$} & $<20$ & 5.9 & 12.3 & 8.6 & 26.8 & 5.7 \\
\hline & $20-24$ & 15.0 & 27.6 & 29.4 & 38.7 & 14.7 \\
\hline & $25-29$ & 23.1 & 23.6 & 25.5 & 19.7 & 23.1 \\
\hline & $30-34$ & 33.3 & 20.5 & 20.1 & 8.7 & 33.6 \\
\hline & $35+$ & 22.7 & 16 & 16.4 & 6.1 & 22.9 \\
\hline \multirow{3}{*}{$\begin{array}{l}\text { Maternal } \\
\text { education }\end{array}$} & $<\mathrm{HS}$ & 11.9 & 27.6 & 38.8 & 40.3 & 11.5 \\
\hline & HS & 22.9 & 34.3 & 37 & 37 & 22.7 \\
\hline & $>\mathrm{HS}$ & 65.2 & 38.2 & 24.2 & 22.8 & 65.8 \\
\hline \multirow{2}{*}{ Payer } & Private/Other & 67.5 & 30.8 & 10.7 & 12 & 68.4 \\
\hline & Public & 32.5 & 69.2 & 89.3 & 88 & 31.6 \\
\hline \multirow{2}{*}{ Marital status } & Married & 72.5 & 40.4 & 18.5 & 16.8 & 73.2 \\
\hline & Not married & 27.5 & 59.6 & 81.4 & 83.2 & 26.8 \\
\hline \multirow{2}{*}{ Parity } & Nulliparous & 44.4 & 43.3 & 35.5 & 47.4 & 44.5 \\
\hline & Multiparous & 55.6 & 56.7 & 64.5 & 52.6 & 55.5 \\
\hline \multirow{2}{*}{ Smoking } & Yes & 14.6 & 37 & 63.8 & 35.1 & 14.1 \\
\hline & No & 85.4 & 63 & 37.2 & 64.9 & 85.9 \\
\hline \multirow{2}{*}{$\begin{array}{l}\text { Low birth } \\
\text { weight } \\
(<2500 \\
\text { grams })\end{array}$} & Yes & 6.5 & 13.6 & 25.4 & 13.2 & 6.9 \\
\hline & No & 93.5 & 86.4 & 74.6 & 86.8 & 93.2 \\
\hline \multirow{2}{*}{$\begin{array}{l}\text { Preterm birth } \\
\text { (<37 weeks) }\end{array}$} & Yes & 10 & 16.2 & 20.9 & 14.6 & 9.8 \\
\hline & No & 90 & 83.9 & 79.2 & 85.4 & 90.2 \\
\hline
\end{tabular}

${ }^{a}$ Mental illness, substance abuse, and intentional injury visit types are not mutually exclusive.

${ }^{\mathrm{b}}$ All relationships of the diagnosis and characteristics, compared to the overall study population without MI, SA and II (not shown) are statistically significant at $\mathrm{p}<.05$, except for race/ethnicity and MI, all three visit types and parity, and LBW and II. 
Table 3: Number and percent of women with hospital visits for mental illness, substance abuse, or intentional injury during pregnancy $(n=3,365)$ and total number and percent of visit types $(n=4,900)^{\mathrm{a}}$

\begin{tabular}{lcccc}
\hline & \multicolumn{2}{c}{ Women } & \multicolumn{2}{c}{ Visits } \\
& $\mathrm{N}$ & $\%$ & $\mathrm{~N}$ & $\%$ \\
\hline Mental illness & 2208 & 1.3 & 3096 & 2.6 \\
Anxiety disorders & 1049 & 0.6 & 1285 & 1.1 \\
Mood disorders & 1229 & 0.7 & 1735 & 1.4 \\
Bipolar affective disorder & 232 & 0.1 & 344 & 0.3 \\
Depression & 1078 & 0.6 & 1425 & 1.2 \\
Substance abuse disorder & 834 & 0.5 & 1473 & 1.2 \\
Intentional injury & 847 & 0.5 & 931 & 0.8 \\
Other-inflicted & 760 & 0.4 & 829 & 0.7 \\
Self-inflicted & 94 & 0.1 & 102 & 0.1 \\
\hline
\end{tabular}

${ }^{\mathrm{a}}$ Mental illness, substance abuse, and intentional injury visit types are not mutually exclusive. 
Table 4: Characteristics of study population with at least one mental illness and one intentional injury visit during pregnancy $(\mathrm{n}=163)^{\mathrm{a}}$

\begin{tabular}{|c|c|c|c|}
\hline Characteristic & & $\mathrm{N}(\%)$ & $\begin{array}{c}\text { Unadjusted odds ratio } \\
(95 \% \mathrm{CI})\end{array}$ \\
\hline \multirow{5}{*}{ Maternal race/ethnicity } & White, non-Hispanic & $87(53)$ & ref \\
\hline & Hispanic & $45(28)$ & $3.0(2.1-4.3)$ \\
\hline & Black, non-Hispanic & $22(14)$ & $2.4(1.5-3.9)$ \\
\hline & Asian/Pacific Islander & * & $*$ \\
\hline & Other & $*$ & $*$ \\
\hline \multirow{5}{*}{ Maternal age, years } & $25-29$ & $29(18)$ & ref \\
\hline & $<20$ & $35(21)$ & $4.8(2.9-7.8)$ \\
\hline & $20-24$ & $68(42)$ & $3.6(2.3-5.6)$ \\
\hline & $30-34$ & $22(14)$ & $0.5(0.3-0.9)$ \\
\hline & $35+$ & $9(5)$ & $0.3(0.1-0.7)$ \\
\hline \multirow{3}{*}{ Maternal education } & $>\mathrm{HS}$ & $40(2.5)$ & ref \\
\hline & $<\mathrm{HS}$ & $66(4.1)$ & $9.1(6.1-13.4)$ \\
\hline & HS & $56(3.5)$ & $4.0(2.7-6.0)$ \\
\hline \multirow[t]{2}{*}{ Payer } & Private/Other & $21(13)$ & ref \\
\hline & Public & $142(87)$ & $14.1(8.9-22.3)$ \\
\hline \multirow{2}{*}{ Marital status } & Married & $37(2.3)$ & ref \\
\hline & Not married & $126(77)$ & $13.2(11.0-15.9)$ \\
\hline \multirow{2}{*}{ Parity } & Nulliparous & $76(47)$ & ref \\
\hline & Multiparous & $86(53)$ & $0.9(0.7-1.2)$ \\
\hline \multirow{2}{*}{ Smoking } & No & $100(61)$ & ref \\
\hline & Yes & $63(39)$ & $3.7(2.7-5.1)$ \\
\hline
\end{tabular}

${ }^{\mathrm{a}}$ Due to missing data, some categories have less than 163 women.

* Cell sizes are suppressed for less than 7 according to data requirements from the Division of Health Care Finance and Policy. 
Table 5: Characteristics of study population with at least one substance abuse and one intentional injury visit during pregnancy $(\mathrm{n}=69)^{\mathrm{a}}$

\begin{tabular}{|c|c|c|c|}
\hline Characteristic & & $\mathrm{N}(\%)$ & $\begin{array}{c}\text { Unadjusted odds ratio } \\
(95 \% \mathrm{CI})\end{array}$ \\
\hline \multirow{5}{*}{ Maternal race/ethnicity } & White, non-Hispanic & $52(75.4)$ & ref \\
\hline & Hispanic & $10(14.5)$ & $1.1(0.6-2.2)$ \\
\hline & Black, non-Hispanic & $7(10.1)$ & $1.3(0.6-2.8)$ \\
\hline & Asian/Pacific Islander & 0 & - \\
\hline & Other & 0 & - \\
\hline \multirow{5}{*}{ Maternal age, years } & $25-29$ & $15(21.7)$ & ref \\
\hline & $<20$ & $9(13)$ & $2.4(1.0-5.4)$ \\
\hline & $20-24$ & $24(34.8)$ & $2.5(1.3-4.7)$ \\
\hline & $30-34$ & $11(15.9)$ & $0.5(0.2-1.1)$ \\
\hline & $35-39$ & $10(14.5)$ & $0.7(0.3-1.6)$ \\
\hline \multirow{3}{*}{ Maternal education } & $>\mathrm{HS}$ & $15(22.1)$ & ref \\
\hline & $<\mathrm{HS}$ & $24(35.3)$ & $8.8(4.6-16.7)$ \\
\hline & HS & $29(42.7)$ & $5.5(3.0-10.3)$ \\
\hline \multirow[t]{2}{*}{ Payer } & Private/Other & $*$ & ref \\
\hline & Public & $63(91.3)$ & $21.9(9.5-50.5)$ \\
\hline \multirow{2}{*}{ Marital status } & Married & $15(22.1)$ & ref \\
\hline & Not married & $53(77.9)$ & $9.3(5.2-16.5)$ \\
\hline \multirow{2}{*}{ Parity } & Nulliparous & $28(41.8)$ & ref \\
\hline & Multiparous & $39(58.2)$ & $1.1(0.7-1.8)$ \\
\hline \multirow{2}{*}{ Smoking } & No & $30(43.5)$ & ref \\
\hline & Yes & $39(56.5)$ & $7.6(4.7-12.3)$ \\
\hline
\end{tabular}

${ }^{a}$ Due to missing data, some categories have less than 69 women.

*Cell sizes are suppressed for less than 7 according to data requirements from the Division of Health Care Finance and Policy. 
Table 6: Adjusted odds ratios of mental illness, substance abuse, and intentional injuries for low birth weight and preterm birth

\begin{tabular}{lcc} 
& & \\
& Low birth weight & Preterm birth \\
\cline { 2 - 3 } & aOR (95\% CI) & aOR (95\% CI) \\
\hline Mental illness $^{\mathrm{a}}$ & $1.6(1.4-1.8)$ & $1.6(1.4-1.9)$ \\
Substance abuse $^{\mathrm{a}}$ & $3.8(3.1-4.7)$ & $2.2(1.8-2.8)$ \\
Intentional injury $^{\mathrm{a}}$ & $1.4(1.1-1.8)$ & $1.3(1.1-1.7)$ \\
Mental illness/ Intentional injury $^{\mathrm{b}}$ & $1.3(0.8-2.2)$ & $1.2(0.7-2.0)$ \\
Substance abuse/ Intentional injury $^{\mathrm{c}}$ & $5.3(3.9-7.3)$ & $2.7(1.3-5.7)$ \\
\hline
\end{tabular}

${ }^{a}$ Adjusted for age, race, payer, marital status, smoking.

${ }^{\mathrm{b}}$ Adjusted for age, race, payer, marital status, smoking, substance abuse.

${ }^{\mathrm{c}}$ Adjusted for age, race, payer, marital status, smoking, mental illness. 


\section{References}

1. Bennett HA, Einarson A, Taddio A, Koren G, Einarson TR. Prevalence of depression during pregnancy: Systematic review. Obstet Gynecol. 2004 Apr;103(4):698-709.

2. Marcus SM, Flynn HA, Blow FC, Barry KL. Depressive symptoms among pregnant women screened in obstetrics settings. J Womens Health (Larchmt). 2003 May;12(4):373-80.

3. Gavin NI, Gaynes BN, Lohr KN, Meltzer-Brody S, Gartlehner G, Swinson T. Perinatal depression: A systematic review of prevalence and incidence. Obstet Gynecol. 2005 Nov;106(5 Pt 1):1071-83.

4. Dayan J, Creveuil C, Herlicoviez M, Herbel C, Baranger E, Savoye C, et al. Role of anxiety and depression in the onset of spontaneous preterm labor. Am J Epidemiol. 2002;155(4):293-301.

5. Hoffman S, Hatch MC. Depressive symptomatology during pregnancy: Evidence for an association with decreased fetal growth in pregnancies of lower social class women. Health Psychol. 2000 Nov;19(6):535-43.

6. Kelly RH, Russo J, Holt VL, Danielsen BH, Zatzick DF, Walker E, et al. Psychiatric and substance use disorders as risk factors for low birth weight and preterm delivery. Obstet Gynecol..। 2002;100(2):297-304.

7. Orr ST, James SA, Blackmore Prince C. Maternal prenatal depressive symptoms and spontaneous preterm births among African-American women in Baltimore, Maryland. Am J Epidemiol. 2002 Nov 1;156(9):797-802.

8. Steer RA, Scholl TO, Hediger ML, Fischer RL. Self-reported depression and negative pregnancy outcomes. J Clin Epidemiol. 1992 Oct;45(10):1093-9. 
9. MacCabe JH, Martinsson L, Lichtenstein P, Nilsson E, Cnattingius S, Murray RM, et al. Adverse pregnancy outcomes in mothers with affective psychosis. Bipolar Disord. 2007;9(3):305-9.

10. Miller LJ. Psychiatric disorders during pregnancy. In: Stotland NL, Steward DE, eds. Psychological Aspects of Women's Health Care: The Interface Between Psychiatry and Obstetrics and Gynecology. 2001:51-66.

11. Lee AM, Lam SK, Sze Mun Lau SM, Chong CSY, Chui HW, Fong DYT.

Prevalence, course, and risk factors for antenatal anxiety and depression. Obstet Gynecol. 2007 Nov;110(5):1102-12.

12. Nilsson E, Lichtenstein P, Cnattingius S, Murray RM, Hultman CM. Women with schizophrenia: Pregnancy outcome and infant death among their offspring. Schizophr Res. 2002;58(2-3):221-9.

13. Lester BM, Andreozzi L, Appiah L. Substance use during pregnancy: Time for policy to catch up with research. Harm Reduction Journal. 2004;1(5):1-44.

14. Results from the 2005 National Survey on Drug Use and Health: National findings [homepage on the Internet]. 2008. Available from:http://oas.samhsa.gov/nsduh/2k5nsduh/2k5results.htm.

15. Bailey BA, Sokol RJ. Pregnancy and alcohol use: Evidence and recommendations for prenatal care. Clin Obstet Gynecol. 2008;51(2):436.

16. Zuckerman B, Frank D, Brown E. Overview of the effects of abuse and drugs on pregnancy and offspring. In: Chiang CN, Finnegan LP, editors. Medications Development for the Treatment of Pregnant Addicts and Their Infants. Rockville, MD: National Institute on Drug Abuse; 1995. pp. 16-38. NIDA Research Monograph 149. 
NIH Publication No. 953891.

17. Shankaran S, Lester BM, Das A, Bauer CR, Bada HS, Lagasse L, Higgins R. Impact of maternal substance use during pregnancy on childhood outcome. Semin Fetal Neonatal Med.12 (2):143- 50, 2007

18. Gazmararian JA, Lazorick S, Spitz AM, Ballard TJ, Saltzman LE, Marks JS. Prevalence of violence against pregnant women. JAMA. 1996;275(24):1915-20. 19. Nannini A, Lazar J, Berg C, Barger M, Tomashek K, Cabral H, et al. Physical injuries reported on hospital visits for assault during the pregnancy-associated period. Nurs Res. 2008;57(3):144.

20. Boy A, Salihu HM. Intimate partner violence and birth outcomes: A systematic review. Int J Fertil Womens Med. 2004;49(4):159-64.

21. Amaro H. Violence during pregnancy and substance use. Am J Public Health. 1990;80(5):575-9.

22. Martin SL, Beaumont JL, Kupper LL. Substance use before and during pregnancy: Links to intimate partner violence. Am J Drug Alcohol Abuse. 2003 Aug;29(3):599-617. 23. Martin SL. Violence and substance use among North Carolina pregnant women. Am J Public Health. 1996;86(7):991-8.

24. Martin SL, Kilgallen B, Dee DL, Dawson S, Campbell J. Women in a prenatal care/substance abuse treatment program: Links between domestic violence and mental health. Matern Child Health J. 1998;2(2):85-94.

25. Martin SL, Clark KA, Lynch SR, Kupper LL, Cilenti D. Violence in the lives of pregnant teenage women: Associations with multiple substance use. Am J Drug Alcohol Abuse. 1999;25(3):425-40. 
26. Horrigan TJ, Schroeder AV, Schaffer RM. The triad of substance abuse, violence, and depression are interrelated in pregnancy. J Subst Abuse Treat. 2000;18(1):55-8.

27. Velez ML, Montoya ID, Jansson LM, Walters V, Svikis D, Jones HE, et al. Exposure to violence among substance-dependent pregnant women and their children. J Subst Abuse Treat. 2006;30(1):31-8.

28. Hedin LW, Janson PO. Domestic violence during pregnancy. The prevalence of physical injuries, substance use, abortions and miscarriages. Acta Obstet Gynecol Scand 2000;79:625-30

29. Tuten M, Jones HE, Tran G, Svikis DS. Partner violence impacts the psychosocial and psychiatric status of pregnant, drug-dependent women. Addict Behav. 2004;29(5):1029-34.

30. Bacchus L, Mezey G, Bewley S. Domestic violence: prevalence in pregnant women and associations with physical and psychological health. Eur J Obst \& Gyn \& Reprod Biology, 2003;113, 6-11.

31. Lovisi GM, Lopez JRRA, Coutinho ESF, Patel V. Poverty, violence and depression during pregnancy: A survey of mothers attending a public hospital in Brazil. Psychol Med. 2005;35(10):1485-92.

32. Ferri CP, Mitsuhiro SS, Barros MC, Chalem E, Guinsburg R, Patel V, et al. The impact of maternal experience of violence and common mental disorders on neonatal outcomes: A survey of adolescent mothers in Sao Paulo, Brazil. BMC Public Health. 2007 Aug 16;7:209.

33. Rosen D, Seng JS, Tolman RM, Mallinger G. Intimate partner violence, depression, and posttraumatic stress disorder as additional predictors of low birth weight infants 
among low-income mothers. J Interpers Violence. 2007;22(10):1305.

34. Rodriguez MA, Heilemann MSV, Fielder E, Ang A, Nevarez F, Mangione CM. Intimate partner violence, depression, and PTSD among pregnant Latina women. The Annals of Family Medicine. 2008;6(1):44-52.

35. Clements KM, Barfield WD, Kotelchuck M, Lee KG, Wilber N. Birth characteristics associated with Early Intervention referral, evaluation for eligibility, and program eligibility in the first year of life. Matern Child Health J. 2006;10(5):433-41. 36. Weiss HB. Pregnancy-associated injury hospitalizations in Pennsylvania, 1995. Ann Emerg Med. 1999;34(5).

37. Schoenman JA, Sutton JP, Kintala S, Love D, Maw R. The value of hospital discharge databases [homepage on the Internet]. 2005. Available from: http://www.hcupus.ahrq.gov/reports/final_report.pdf.

38. Lawrence BA, Miller TR, Weiss HB, Spicer RS. Issues in using state hospital discharge data in injury control research and surveillance. Accident Analysis and Prevention. 2007;39(2):319-25.

39. Dietz PM, England L, Callaghan WM, Pearl M, Wier ML, Kharrazi M. A comparison of LMP-based and ultrasound-based estimates of gestational age using linked California live birth and prenatal screening records. Ped Perinat Epidemiol 2007;21(Suppl. 2):6271.

40. Data source: Urban Institute and Kaiser Commission on Medicaid and the uninsured estimates based on the Census Bureau's March 2007 and 2008 Current Population Survey (CPS: Annual social and economic supplements).[homepage on the Internet]. 2007. Available from:http://www.statehealthfacts.org/profileind.jsp?ind=6\&cat=1\&rgn=23. 
41. Urban Institute and Kaiser Commission on Medicaid and the uninsured estimates based on the Census Bureau's March 2007 and 2008 Current Population Survey (CPS: Annual social and economic supplements).[homepage on the Internet]. 2007. Available from:http://www.statehealthfacts.org/profileind.jsp?ind=9\&cat=1\&rgn=23.

42. Tolman RM, Rosen D. Domestic violence in the lives of women receiving welfare: Mental health, substance dependency and economic well-being. Violence Against Women. 2001;7:141-158.45.

43. Domino ME, Morrissey JP, Chung S, Huntington N, Larson MJ, Russell LA. Service use and costs for women with co-occurring mental and substance use disorders and a history of violence. Psychiatric Services. 2005;56(10):1223.

44. Morrissey JP, Jackson EW, Ellis AR, Amaro H, Brown VB, Najavits LM. Twelvemonth outcomes of trauma-informed interventions for women with co-occurring disorders. Psychiatric Services. 2005;56(10):1213.

45. The N-SSATS Report: Mental Health Screenings and Trauma-Related Counseling in Substance Abuse Treatment Facilities [homepage on the Internet]. 2010. Available from:http://oas.samhsa.gov/2k10/313/313Trauma2k10.htm. 